\title{
Research on the Construction Strategy of Knowledge Management System of JLY Company in Guangzhou City
}

\author{
Baosheng Xie \\ Guangzhou College of Technology and Business \\ Guangzhou, China 510850
}

\begin{abstract}
Knowledge management is the process in which enterprises use their intellectual capital to generate wealth. Having a sound knowledge management system is the key to enterprise development. This paper studies the knowledge management system of JLY Company in Guangzhou, analyzes the problems of insufficient innovation ability and insufficient technical level in the knowledge management work, and combines the understanding of the importance of knowledge management on enterprise development. It proposes the construction strategy of knowledge management system of this company.
\end{abstract}

Keywords-intellectual capital; innovation ability; learning organization; knowledge management system; construction strategy

\section{INTRODUCTION}

As a typical knowledge-intensive enterprise, JLY Company in Guangzhou has the defects of insufficient innovation ability and insufficient technical level in its knowledge management system. It is a common defect of most SMEs in China. If it can be solved through in-depth research and discussion, it can achieve the goal of further improving the knowledge management system of SMEs. It has two important implications. First, solving the problem of insufficient innovation ability is conducive to enhancing the vitality of the knowledge management system and improving the self-management ability of enterprises and employees at the knowledge level. Second, solving the problem of insufficient technical level is conducive to improving the structure of knowledge management and maximizing the utility of knowledge management. Therefore, this paper analyzes and explores the problems existing in the knowledge management system of SMEs, and proposes strategies for building knowledge management systems.

\section{Status OF KNOWLEDGE MANAGEMENT SyStem OF JLY COMPANY IN GUANGZHOU CITY}

\section{A. Brief Introduction of JLY Company in Guangzhou City}

Founded in 2004, JLY Company in Guangzhou is an Internet company specializing in Internet information services, vertical information and investment in industry websites. It is a well-known website development and investment operator in Guangzhou. It provides Internet websites with professional websites, pictures and dating services. At present, there are general manager's office, administrative personnel department, planning and finance department, product research and development design department, marketing department and after-sales service department. According to statistics, the company has 111 employees, including 1 general manager, 3 deputy general managers, 4 administrative personnel, 4 personnel in planning and finance department, 23 personnel in product development and design department, 68 personnel in marketing department, and 8 personnel in after-sales service department.

\section{B. Status of Knowledge Management System of JLY Company in Guangzhou City}

The knowledge management system of JLY Company in Guangzhou is mainly based on the knowledge exchange platform between employees. It is embodied in the discussion of the meetings, exchanges and learns within the department. The knowledge units involved in the work of the department are compiled into a book from time to time. And then, it will be submitted to the colleagues who are responsible for the knowledge management. The entire knowledge management system is relatively simple, lacking inter-departmental exchange learning and a coordinating role of a processor, making it difficult to achieve multifaceted knowledge. It fails to achieve its maximum effectiveness.

At the beginning of 2018, the author participated in the research and analysis of the "status of enterprise knowledge management system" in the "Report on the development strategy of JLY Company in Guangzhou". At that time, after organizing a professional training in knowledge management, a total of 111 questionnaires on "the implementation of knowledge management of JLY Company in Guangzhou" were issued. And 111 questionnaires were returned, of which 100 questionnaires were valid questionnaires. The questionnaire is mainly to understand the maturity of knowledge management of JLY Company in Guangzhou city, with a total score of 75 points, of which: 70 points-75 points are in optimization level; 60 
points-70 points are in cooperation level; 45 points-60 points are in reusing level; 30 points-45 points are in cognitive level; 15 points-30 points are in initial level. At the same time, this questionnaire has made the analysis on general situation of five links: "precipitation, sharing, learning, application and innovation" in the knowledge management system, and three main factors of "culture, management and technology" that influence the decisionmaking objectives. The score of each item is 5 points, of which: 5 points are in optimization level; 4 points are in cooperation level; 3 points are in reusing level; 2 points are in cognitive level; 1 point is in initial level.

The details of the survey results are shown in the following table:

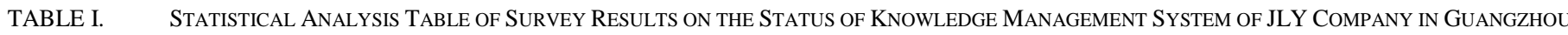
CITY

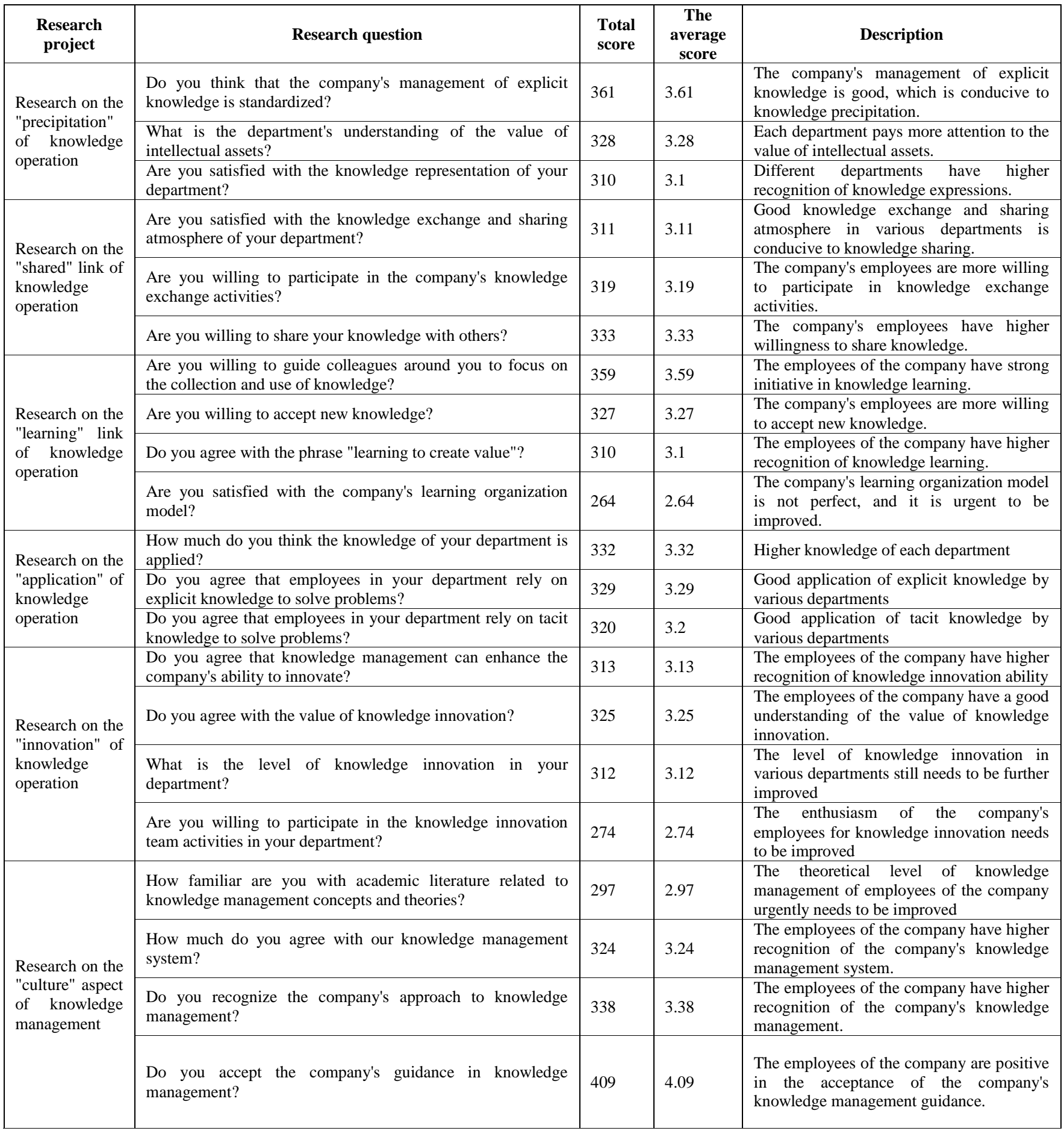




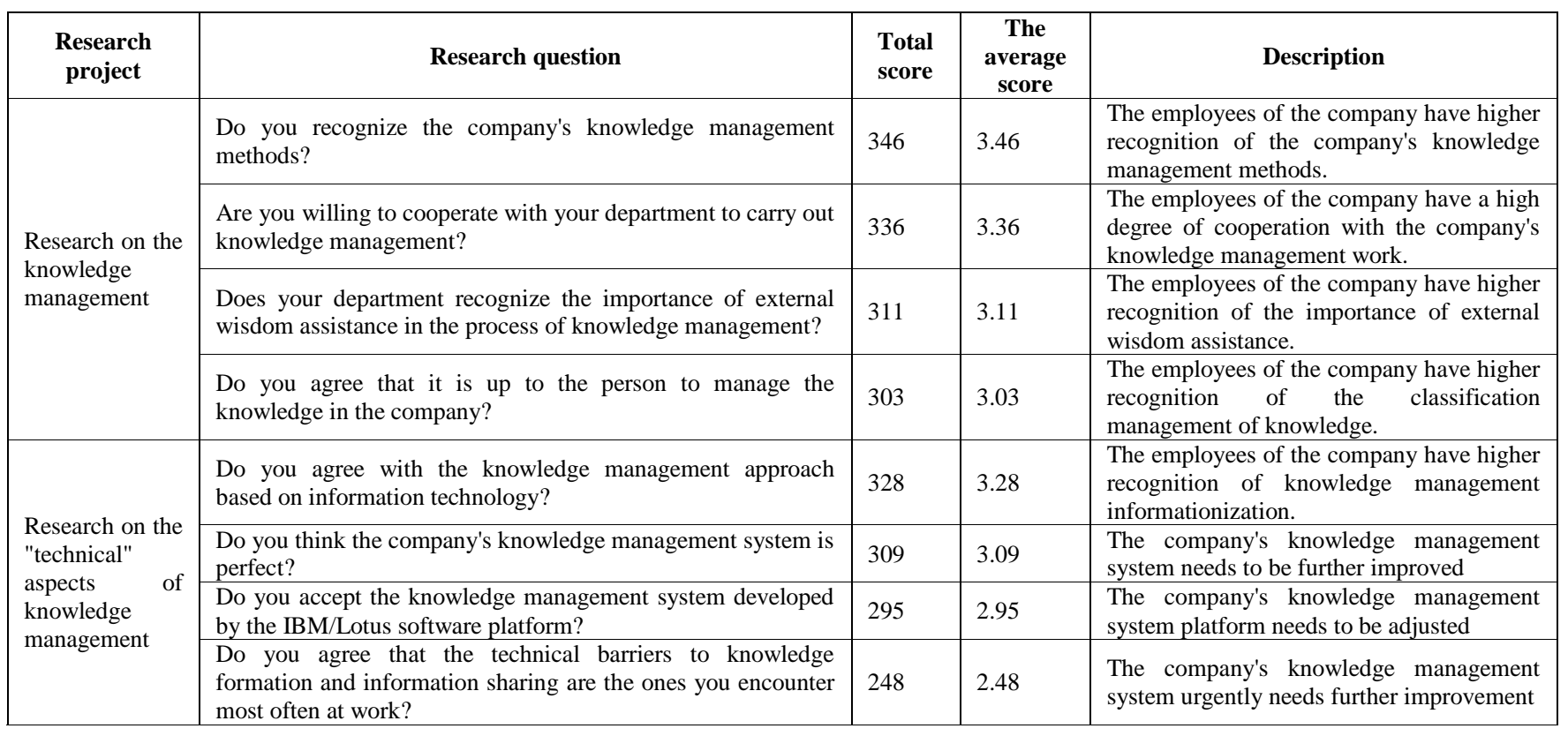

Based on the scores of the above table, we can get the following statistical results. In the first part, a total of 3 small questions are on the "precipitation" of knowledge operation. The total score is 999 points, and the total average is 3.33 points. The second part is the research on "shared" link of knowledge operation. There are 3 small questions. The total score is 963 points, and the overall average is 3.21 points. The third part is the research on "learning" link of the knowledge. There are a total of 4 small questions. The total score is 1260 points. The average score is 3.15 points. The fourth part is the "application" link of knowledge operation, with a total of 3 small questions. The total score is 981 points, and a total average score is 3.27 points. The fifth part is the investigation of the "innovation" of knowledge operation. There are a total of 4 small questions. The total score is 1224 points, and the overall average is 3.06 points. The sixth part is the research on the "cultural" aspect of the knowledge. There are a total of 4 small questions. The total score is 1368 points, and the total average is 3.42 points. The seventh part is the research on the "management" aspect of knowledge management. There are a total of 4 small questions. The total score is 1296 points, and the overall average is 3.24 points. The eighth part is the research on the "technical" aspects of the knowledge. There are a total of 4 small questions. The total score is 1180 points, and the total average is 2.95 points. In addition, the third question of the second part, the third question of the fourth part, the first question of the fifth part, and the fifteen questions of the sixth part, the seventh part, and the eighth part are the reference items for the survey on knowledge management maturity. The total score is 4810 points. The total average score is 48.10 points, and the average is 3.21 points.

According to the comprehensive analysis of the questionnaire survey results, the overall knowledge management maturity of JLY Company is 48.1 points, the average is 3.21 points, and the knowledge management maturity level is in the initial stage of the third level. The company's knowledge management is not optimistic. (As shown in "Fig. 1")

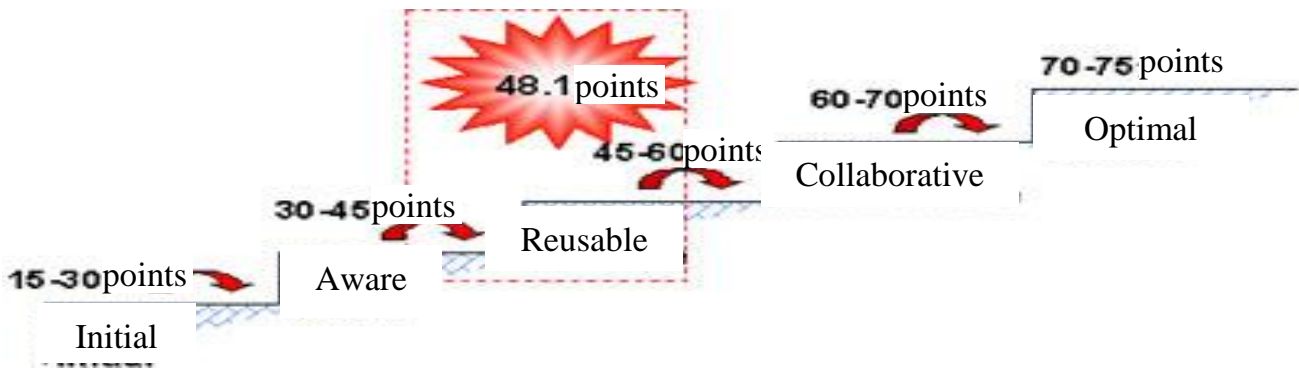

Fig. 1. Status of knowledge management system of JLY Company in Guangzhou city. 
Through the above picture, we can see that the knowledge management of JLY Company is in the leapfrog stage of cognitive level to reusable level. The knowledge management of some advanced enterprises has reached the optimization level. It can be seen that the company's knowledge management is still relatively low. In the early stage of knowledge management development, it is necessary to further improve the management system. It can promote the company's knowledge management from the passive acquisition of knowledge to the innovation of knowledge.

\section{ANALYSIS ON THE PROBLEM OF THE KNOWLEDGE MANAGEMENT SYSTEM OF JLY COMPANY IN GUANGZHOU CITY}

\section{A. Insufficient Innovation Ability}

In the knowledge management of JLY Company, in the five links of "precipitation, sharing, learning, application and innovation" of knowledge operation, knowledge "precipitation" is relatively good, while knowledge "innovation" is insufficient. Among them, the company scored the highest in the "precipitation" of knowledge, with an average of 3.33 points, indicating that JLY Company has realized the importance of knowledge precipitation. However, the company scored relatively low in the "innovation" of knowledge, with an average of 3.06 points. Therefore, JLY Company should pay special attention to the "innovation" and put it into practice. (As shown in "Fig. 2")

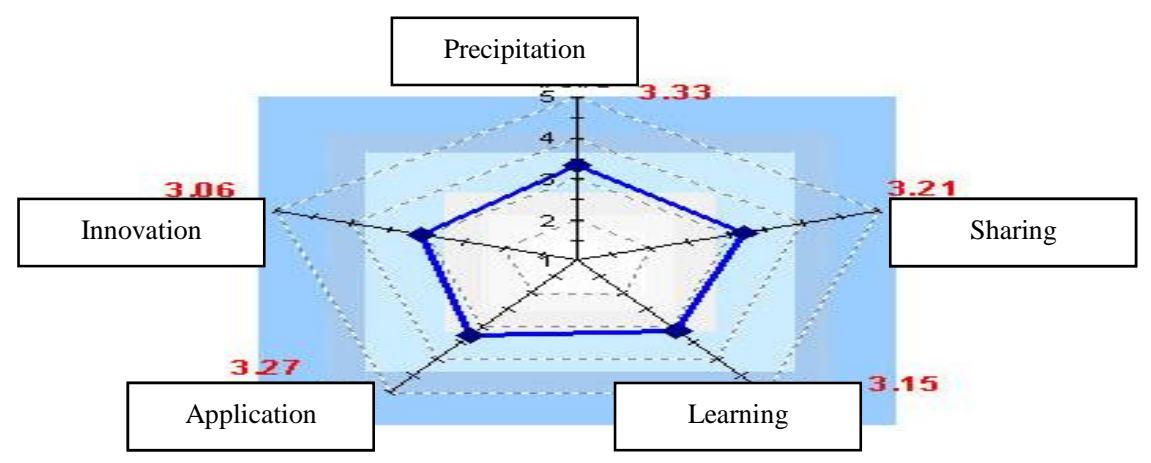

Fig. 2. Status of the five links of knowledge operation of JLY Company in Guangzhou city.

From the above five links, we can know "Precipitation" > "Application" > "Share" > "Learning" > "Innovation".

Knowledge management acts as a bridge to improve the overall innovation and operational capabilities of the company, creating newer and better products. However, insufficient innovation ability of JLY Company's knowledge management system has become a bottleneck for the development.

\section{B. The Technical Level Is Not Enough}

Among the three main factors of "culture, management and technology" that influence the decision-making objectives of JLY Company in Cuangzhou city, "technology" is at the lowest level, which in turn affects the "culture" of knowledge management and the implementation of "management" mechanism. In the "cultural" dimension, it has got the highest score, with an average of 3.42 points. It indicates that the company generally understands the promotion of "culture" and the knowledge management. The score in the "management" dimension is the second, with an average of 3.24 points, indicating that the company also needs to lay a solid foundation in the system construction of knowledge management. The lowest score is obtained in the "technical" dimension, with an average of 2.95 points, indicating that the company is in urgent need of improvement in supporting the technology of knowledge management. (As shown in "Fig. 3)

The knowledge resources have great value. The systematic and efficient management of knowledge resources can create greater value. We can know the reason why knowledge management is important to the development of modern enterprises. Knowledge management is a goal-oriented process. While integrating the knowledge resources of enterprises, it re-creates knowledge and applies it to the development of enterprises, enhances the core competitiveness of enterprises, and finally achieves their decision-making goals. However, JLY Company has insufficient technical level to support knowledge management, which has affected the construction of a good knowledge management system. 


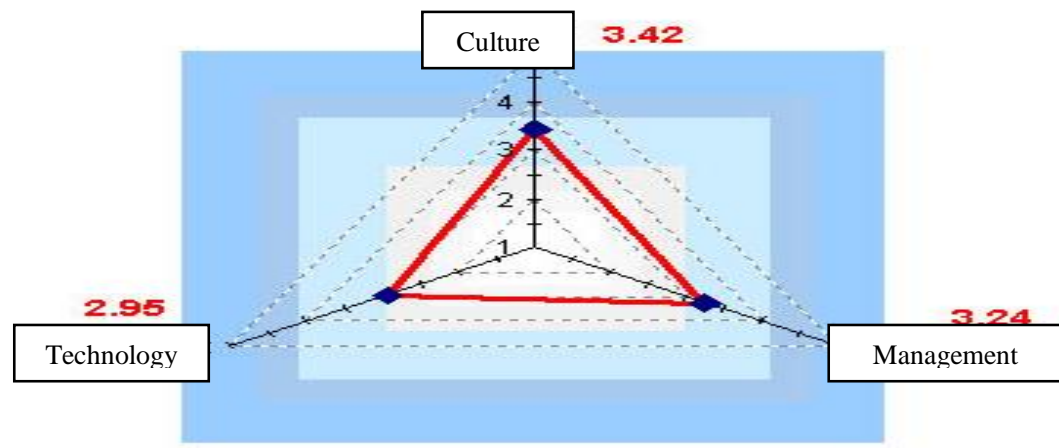

Fig. 3. Status of the three elements of decision-making objectives of JLY Company in Guangzhou city.

Data source: data comes from product development and design department of JLY Company in Guangzhou city. Guangzhou JLY company development strategy report. March 8, 2018

IV. THE CONSTRUCTION STRATEGY OF KNOWLEDGE MANAGEMENT SYSTEM OF JLY COMPANY IN GUANGZHOU CITY

The knowledge management of JLY Company is still in the initial stage of reusable level. It should strengthen knowledge management of the enterprise and build an optimized knowledge management system. The process is shown as the following:

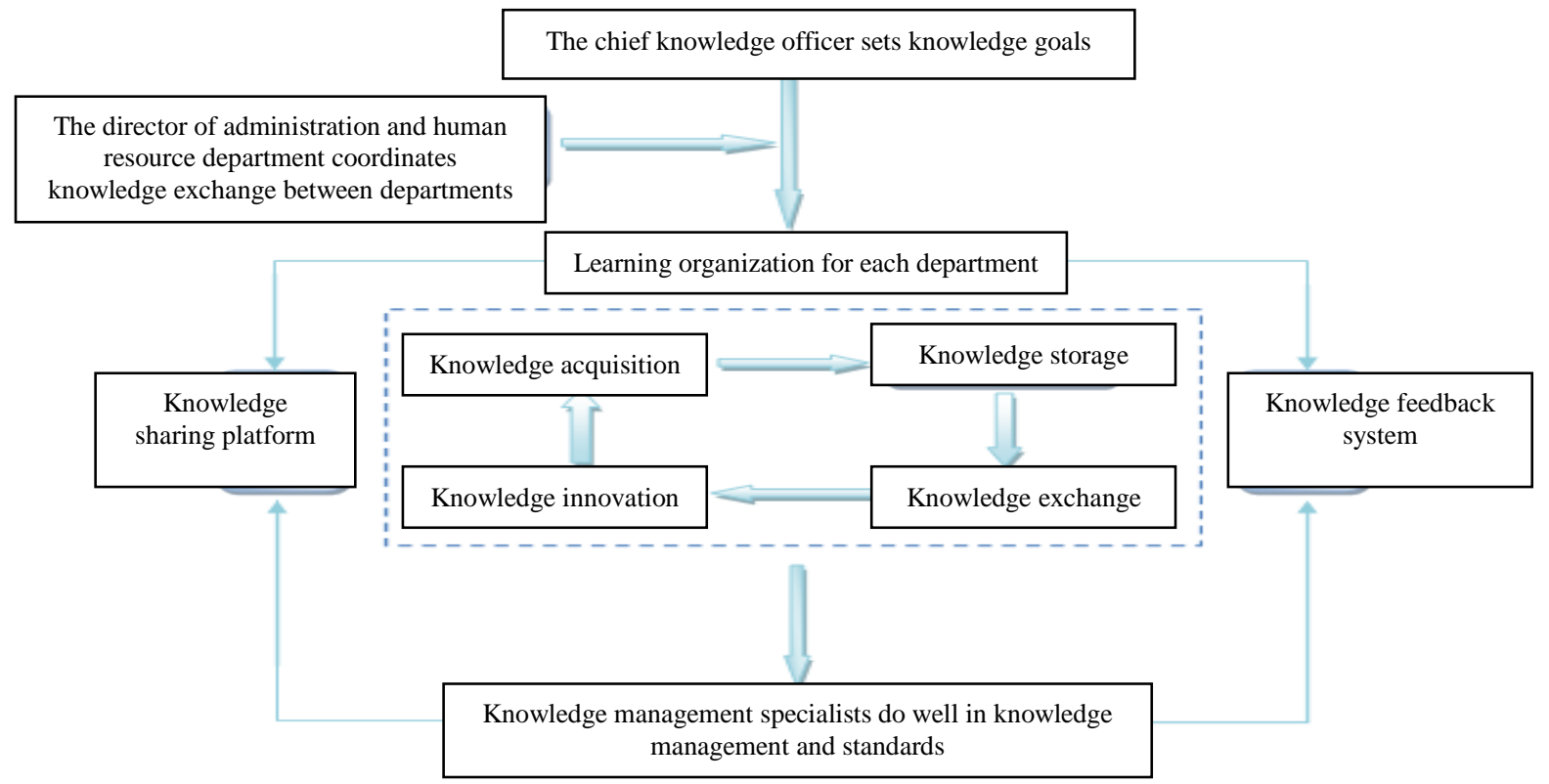

Fig. 4. Flowchart of knowledge management system.

According to the flow chart of knowledge management system, this paper proposes five-point system construction strategy:

\section{A. Having the Support and Attention of Senior Management of the Enterprise}

First, the chief knowledge officer should be promoted to the deputy general manager or above. The main task is to guide enterprises to establish a sound knowledge management system, transform the knowledge resources of the enterprise into the maximum benefit, motivate employees to share knowledge and make the innovation, and improve the competitiveness of enterprises. The director of the administrative personnel department is responsible for coordinating knowledge exchange and sharing among departments.

Second is to set up a knowledge management specialist. His main responsibilities are to understand the basic situation of the enterprise, understand the information needs within the enterprise, and create an environment that promotes learning, accumulates knowledge and information sharing, and enables each employee to recognize the 
benefits of knowledge sharing. and make contribution to the enterprise's knowledge base. The knowledge management specialist should supervise and ensure that the quality, depth and style of knowledge are consistent with the development of the enterprise. He collects and sorts the knowledge information of each department, stores it in the employee library, and uploads it to the network sharing platform. He should ensure the update of information and the normal operation of knowledge base facilities. The knowledge management specialist should strengthen knowledge integration, generate new knowledge, and promote the process of knowledge sharing.

Third, the company's meetings will be convened by the chief knowledge officer on a regular basis to conduct work exchanges among employees throughout the company to enhance knowledge sharing, integration and innovation.

\section{B. The Enterprise Managers Get Out of the Misunderstanding of Knowledge Management}

First, the chief knowledge officer leads the enterprise knowledge management system. With the assistance of the human resources director, the coordination between departments and employees is done. Everyone can accept the model of knowledge management from ideological form, construct a psychological contract, and gradually agree with the goals of the organization.

Second, the chief knowledge officer regularly convene the heads of various departments to hold meetings, use brainstorming forms to express their opinions. The knowledge management commissioner will make a record and select new information that is conducive to the development of the enterprise. After the approval by the chief knowledge officer, knowledge management commissioner should upload to the network sharing platform. The general staff of each department inform the personnel of the department to make information exchange and learning. Through this breakthrough of the conventional management mode, the knowledge management is improved from the technical level, and the utility of knowledge management is maximized.

\section{The Enterprise Shall Strengthen Publicity and Establish an Implementation Plan}

First, we should educate employees and make publication within the company, such as regularly holding knowledge lectures, managing salons, and exchanging experiences with other peers. The vast number of employees can quickly accept and master knowledge management methods to achieve knowledge management consensus.

Second, we should determine the guidelines, strategies and plans for implementing knowledge management. According to the current situation of the enterprise, the introduction of knowledge management must first improve the quality of management personnel. In addition to adopting education and training methods, the company can also use the means of survival of the fittest to eliminate a batch of obsolete managers.
Third, the company can do three to five years of adaptation planning to strengthen knowledge management. The management team can grow up and have a preliminary level of knowledge operation.

Fourth, under the gradual integration of business policies and business strategies, it will lay a solid foundation for the company to improve its knowledge management system.

\section{Establishing a Learning Organization Within the Enterprise}

First, it is necessary to use modern technological means, especially information technology. And we can establish various forms of enterprise knowledge networks as much as possible. It can create basic conditions for the exchange and sharing of knowledge.

Second, we must create an environment that encourages the exchange and sharing of knowledge in various ways. Everyone can share information. The information and information in the human brain that can't be complied can be connected in this appropriate environment. It can ensure the company's creative activities.

Therefore, establishing a learning organization within the enterprise is the best way to build a knowledge exchange and sharing platform. It is also a source of motivation for enterprise knowledge innovation. This method can solve the problem of insufficient knowledge innovation ability of JLY Company in Guangzhou city.

\section{E. Introducing Incentive Mechanism, Establishing Normative and Review System and Feedback System}

First, an effective incentive mechanism should be established, such as the establishment of the "Knowledge Contribution Award", which regularly conducts selections for all employees and gives certain material rewards to encourage employees to actively provide their own hidden knowledge for enterprise sharing. And the employees strive to carry out knowledge innovation.

Second, it is necessary to establish a standardization and evaluation system, follow the PDCA cycle, and do a good knowledge management work plan in accordance with the order. Also, it should make the implementation according to the quality and quantity in the specific conditions, do good follow-up inspection, and conduct regular overall work review.

Third, a feedback system for knowledge management should be established. In the implementation process, knowledge management will inevitably have some problems and changes. Through the feedback system of knowledge management, this information can be timely fed back to the knowledge management specialist. The knowledge management specialist can quickly and accurately take corresponding measures to solve the problems, reduce the knowledge management cost of the enterprise, and enable the knowledge management to proceed smoothly. Thereby, it will improve the effectiveness of knowledge management of the enterprise. 
Therefore, JLY Company in Guangzhou city can improve the knowledge management system and form an optimized knowledge management structure by introducing incentives and doing the four tasks of planning, implementation, inspection and evaluation, and continuously self-reviewing and self-improvement.

\section{CONCLUSION}

In short, knowledge management is a kind of catering measures that are important to the organization's adaptability, organizational survival, organizational capacity, etc., when it is facing increasing non-continuous environmental changes. It is also a knowledge resource for enterprises. At the same time, the enterprise's knowledge resources are fully developed and effectively utilized. Therefore, in the trend of knowledge economy, JLY Company in Guangzhou city urgently needs to build a sound knowledge management system to improve its core competitiveness.

\section{REFERENCES}

[1] Product Development and Design Department of JLY Company in Guangzhou city. Development Strategy Report of JLY Company in Guangzhou city [R]. Guangzhou JLY Company, 2018.

[2] Shen Enping. Knowledge Management and Organizational Learning [M]. Zhejiang University Press, 2017.

[3] Cheng Jia. Study hard: a guide to personal knowledge management [M]. CITIC Publishing House, 2017.

[4] Xia Shuzhang. Introduction to Knowledge Management [M]. Sun Yat-sen University Press, 2017.

[5] Chen Wenwei, Chen Sheng. Knowledge Engineering and Knowledge Management (Second Edition) [M]. Tsinghua University Press, 2016.

[6] Ge Xinhong, Huang Sihan. Doing knowledge management with us [M]. Peking University Press, 2014. 